RESIDENT

\& FELLOW

SECTION

Section Editor

Mitchell S.V. Elkind,

MD, MS
Pearls \& Oy-sters:

\section{Reversible cerebral vasoconstriction syndrome precipitated by ascent to high altitude}

William P. Neil, MD*

Valerie Dechant, $\mathrm{MD}^{*}$ Jackie Urtecho, MD

Address correspondence and reprint requests to Dr. Valerie Dechant, University of North Carolina, Department of Neurology, 101 Manning Drive, Chapel Hill, NC 27517

Valej78@aol.com
CLINICAL PEARL Reversible cerebral vasoconstriction syndrome (RCVS) is characterized by severe headache with or without neurologic findings in the setting of multifocal vasoconstriction of the cerebral arteries, which resolves in 1-3 months. Many vasoactive agents have been proposed as triggers for RCVS. We review a case of RCVS and propose altitude sickness as a trigger.

CASE REPORT A 50-year-old woman flew from Philadelphia (elevation $43 \mathrm{ft}$ ) to the mountains of Colorado (elevation 9,000 ft) for a vacation. The morning after her arrival, she drove 30 minutes to a park at 12,000 ft. Within an hour of hiking at the park, she developed a mild holocranial headache. The pain abated with rest, and that afternoon, she returned to her cabin at 9,000 ft. That night, however, she awoke with a sudden, severe, holocranial, throbbing headache, which was exacerbated by activity. She had no nausea, vomiting, or focal neurologic symptoms. At a local clinic, her blood pressure was elevated at 184/112 mm Hg. Examination and head CT were normal. She was diagnosed with altitude sickness, prescribed acetazolamide, and instructed to descend to a lower altitude. The following day, she moved to an elevation of 5,800 feet; however, the headache persisted, and she returned to Philadelphia. The next morning, she had mild intermittent headaches. She felt confused. She could not read scrolling text from her television and was unable to recap her lip liner.

At the emergency department, her blood pressure was $170 / 89 \mathrm{~mm} \mathrm{Hg}$, and she had spatial disorientation and gait ataxia. She did not have neglect, vision loss, weakness, or encephalopathy. Head CT showed a small, distal, right parietal convexity subarachnoid hemorrhage (figure 1A). An MRI with magnetic resonance angiography and magnetic resonance venography showed no evidence of stroke, sinus thrombosis, vasoconstriction, aneurysm, or other vascular abnormality.

The next day, her symptoms worsened. She developed left-sided neglect, left arm weakness, and a right gaze preference. Her visual acuity was 20/70 in both eyes. She was able to see the examiner's finger, but could not tell in which direction it pointed. She had complete geographic disorientation. An EEG showed no seizure activity. Arterial blood gas was unremarkable. CT angiogram showed multiple areas of focal narrowing within the proximal and distal anterior and posterior circulation, including the anterior, middle, and posterior cerebral arteries and the basilar artery. MRI showed areas of diffusion restriction in bilateral posterior cerebral artery territories (figure 1B).

Normal saline was started to maintain a mean arterial pressure (MAP) greater than $90 \mathrm{~mm} \mathrm{Hg}$. Nimodipine and high-dose steroids were started. A vasculitis workup that included erythrocyte sedimentation rate, C-reactive protein, antinuclear antibodies, rheumatoid factor, complement, Sjögren antibodies, and double-stranded DNA was negative and steroids were tapered. Lumbar puncture was not performed.

The next day, her vision diminished to light recognition only. A CT perfusion scan showed bilateral posterior watershed infarcts. Neo-Synephrine was used to keep her MAP between 100 and $110 \mathrm{~mm}$ $\mathrm{Hg}$. Conventional angiogram was performed. Multiple areas of vessel constriction were noted in the anterior and posterior circulation involving large and small arteries (figure 2).

At the higher blood pressure, her vision improved to 20/200, and her left arm strength improved. She had alexia, acalculia, simultagnosia, ocular apraxia, a right inferior quadrantanopia, and proprioceptive deficits.

Six weeks later, the patient was able to walk and had minimal left hemiparesis. Depth perception

*These authors contributed equally to this work.

From the Department of Neurology (W.P.N., J.U.), Thomas Jefferson University Hospital, Philadelphia, PA; and Department of Neurology (V.D.), University of North Carolina, Chapel Hill.

Disclosure: The authors report no disclosures. 
Figure 1 Initial head CT and MRI diffusion
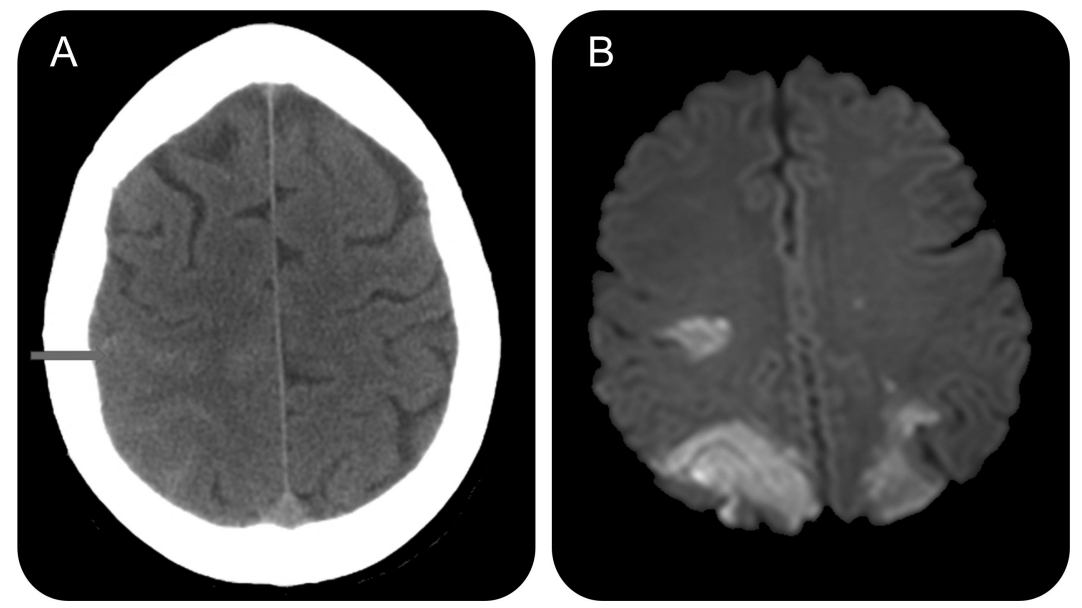

(A) Noncontrast head CT obtained upon admission shows a small right parietal convexity subarachnoid hemorrhage. (B) MRI diffusion obtained after the patient deteriorated. Bilateral posterior cerebral artery territory infarcts are shown.

had improved. She continued to have a right inferior quadrantanopia, simultagnosia, and ocular apraxia. CT angiogram at the at time showed resolution of vasoconstriction (figure 3). By 6 months, her weakness and visual symptoms had resolved except for a right inferior quadrantanopia.

Based on the severe, sudden nature of the headache, neurologic impairments, and the presence of reversible segmental vasospasm, the diagnosis of RCVS was favored.

Figure 2 Left lateral internal carotid artery (ICA) angiogram

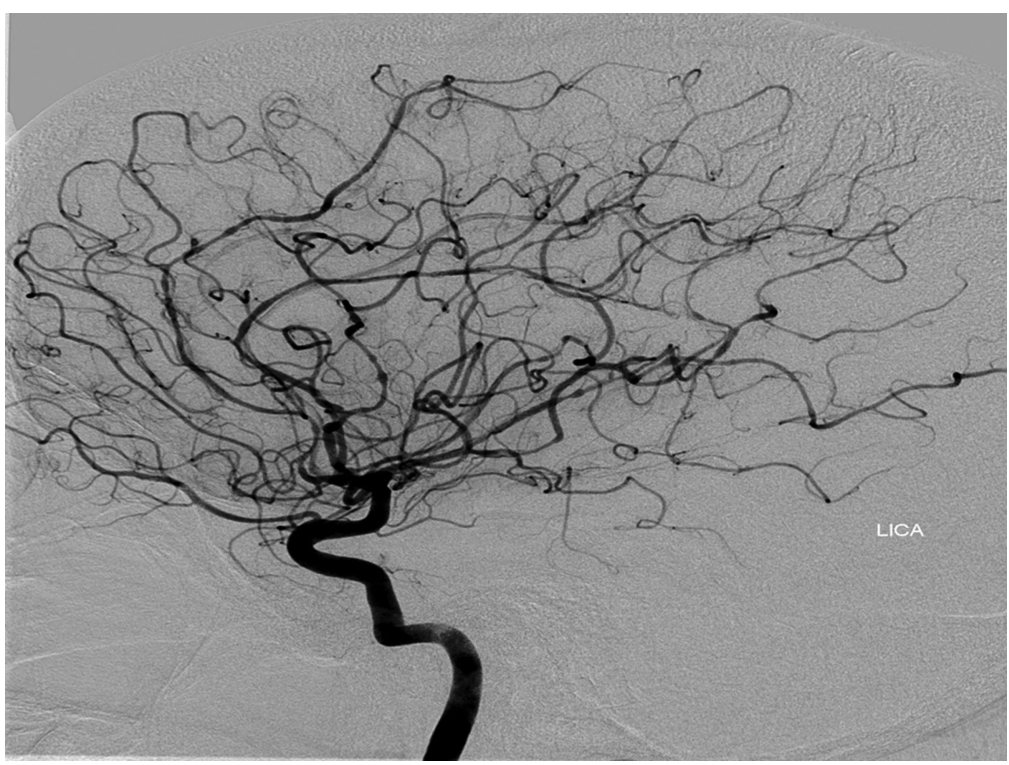

A left lateral projection angiogram with ICA injection shows diffuse vasospasm in large and small vessels in multiple territories.
DISCUSSION RCVS is a unifying term used to describe a clinical syndrome characterized by sudden severe headache, fluctuating neurologic deficits, and fully reversible segmental vasoconstriction of the medium and large cerebral arteries. ${ }^{1}$ It was initially described by Call et al. ${ }^{2}$ in 1988. Other names for RCVS have included benign angiopathy of the CNS, Call-Fleming syndrome, postpartum angiopathy, and drug-induced vasospasm.

Patients with RCVS typically present with thunderclap or severe headache. In mild cases, headache may be the only symptom of RCVS. Altered mental status, seizures, and visual disturbances have also been reported. ${ }^{1}$ Alterations in hemodynamics can lead to hemorrhage or ischemic stroke and cause permanent disability or death. Cortical subarachnoid hemorrhage (cSAH) is a rare but reported complication of RCVS. ${ }^{3} \mathrm{~A}$ recent case series suggests that RCVS may be the most common cause of atraumatic cSAH in younger patients. ${ }^{3}$

RCVS commonly affects young, healthy people. It is most common in women of childbearing age. Precipitating factors for RCVS include eclampsia, the peripartum period, and exposure to vasoactive substances, including nasal decongestants, triptans, and selective serotonin reuptake inhibitors. ${ }^{1,4}$ We propose that altitude-related illness (ARI) may also trigger RCVS.

The pathophysiology of RCVS is poorly understood. Transient alterations in vascular tone modulated by the sympathetic nervous system are suspected to play a central role. ${ }^{5}$ Many of the accepted triggers for RCVS are vasoactive. ARI, including high-altitude headache and altituderelated cerebral edema, is thought to be caused, at least in part, by impaired autoregulation due to vasoreactivity. ${ }^{6}$ Vasoconstriction at high altitude may be triggered by hypocapnia or hypoxic compromise of vasomotor tone. ${ }^{6,7}$ The resulting vasospasm has been proposed to cause otherwise unexplained cases of SAH and cortical blindness in hikers at high altitude. ${ }^{7}$

There is no standardized treatment for RCVS. The use of nimodipine has been suggested but not formally studied. ${ }^{1,4}$ Discontinuation of vasoactive substances is reasonable. Clinical outcomes for patients with RCVS are typically good in the absence of ischemic stroke. ${ }^{4}$ In patients with ischemic stroke, outcome is dependent on the extent of infarction.

RCVS is an uncommon and likely underrecognized entity. It is a diagnosis of exclusion and therefore, clinical suspicion is important to its detection. In this case, the onset of ARI and RCVS 
Figure 3 CT angiogram at admission and 6 weeks demonstrating reversible cerebral vasoconstriction in the basilar artery

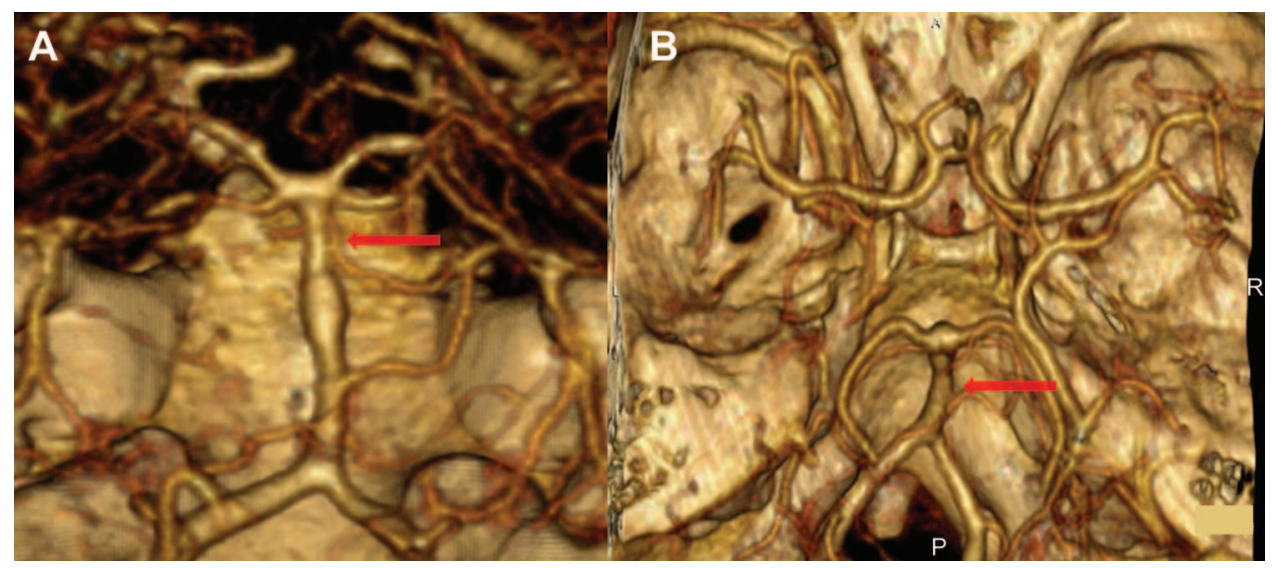

(A) CT angiogram obtained on admission demonstrating areas of vasoconstriction and dilatation in the posterior circulation. (B) CT angiogram obtained at 6 weeks demonstrating resolution of the previously seen vasoconstriction.

were temporally related. We hypothesize that vasoreactivity associated with ARI precipitated RCVS in this patient.

\section{REFERENCES}

1. Ducros A, Boukobza M, Porcher R, Sarov M, Valade D, Bousser MG. The clinical and radiological spectrum of reversible cerebral vasoconstriction syndrome: a prospective series of 67 patients. Brain 2007;130:3091-3101.

2. Call GK, Fleming MC, Sealfon S, Levine H, Kistler JP, Fisher CM. Reversible cerebral segmental vasoconstriction. Stroke 1988;19:1159-1170.

3. Kumar S, Goddeau RP Jr, Selim MH, et al. Atraumatic convexal subarachnoid hemorrhage: clinical presenta- tion, imaging patterns, and etiologies. Neurology 2010; 74:874-875.

4. Calabrese LH, Dodick DW, Schwedt TJ, Singhal AB. Narrative review: reversible cerebral vasoconstriction syndromes. Ann Intern Med 2007;146:34-44.

5. Schwedt T, Matharu MS, Dodick DW. Thunderclap headache. Lancet Neurol 2006;5:621-631.

6. Wilson MH, Newman S, Imray CH. The cerebral effects of ascent to high altitudes. Lancet Neurol 2009;8:175191.

7. Basnyat B, Tianyi W, Gertsch JH. Neurological conditions at altitude that fall outside the usual definition of altitude sickness. High Altitude Med Biol 2004;5:171179. 


\section{Neurology}

\section{Pearls \& Oy-sters: Reversible cerebral vasoconstriction syndrome precipitated by ascent to high altitude}

William P. Neil, Valerie Dechant and Jackie Urtecho

Neurology 2011;76; 7 -e9

DOI 10.1212/WNL.0b013e3182061ae7

\section{This information is current as of January 10, 2011}

\section{Updated Information \&} Services

References

Subspecialty Collections

Permissions \& Licensing

Reprints including high resolution figures, can be found at: http://n.neurology.org/content/76/2/e7.full

This article cites 7 articles, 2 of which you can access for free at: http://n.neurology.org/content/76/2/e7.full\#ref-list-1

This article, along with others on similar topics, appears in the following collection(s):

\section{All Cerebrovascular disease/Stroke}

http://n.neurology.org/cgi/collection/all_cerebrovascular_disease_strok e

All Headache

http://n.neurology.org/cgi/collection/all_headache

Subarachnoid hemorrhage

http://n.neurology.org/cgi/collection/subarachnoid_hemorrhage

Information about reproducing this article in parts (figures,tables) or in its entirety can be found online at:

http://www.neurology.org/about/about_the_journal\#permissions

Information about ordering reprints can be found online: http://n.neurology.org/subscribers/advertise

Neurology ${ }^{\circledR}$ is the official journal of the American Academy of Neurology. Published continuously since 1951 , it is now a weekly with 48 issues per year. Copyright Copyright $@ 2011$ by AAN Enterprises, Inc.. All rights reserved. Print ISSN: 0028-3878. Online ISSN: 1526-632X.

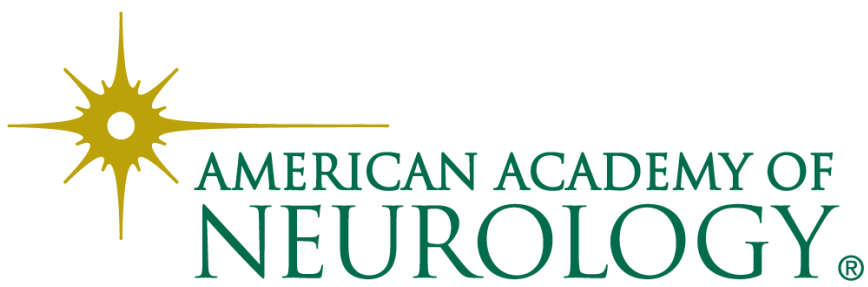

